\title{
Aging, human immunodeficiency virus, and bone health
}

This article was published in the following Dove Press journal:

Clinical Interventions in Aging

13 September 2010

Number of times this article has been viewed

\author{
Kim C Mansky \\ Division of Orthodontics, \\ Department of Developmental and \\ Surgical Sciences, School of Dentistry, \\ University of Minnesota, Minneapolis, \\ MN, USA
}

\begin{abstract}
Highly active antiretroviral therapy (HAART) has had a profound impact on improving the long-term prognosis for individuals infected with human immunodeficiency virus (HIV). HAART has been available for close to two decades, and now a significant number of patients with access to HAART are over the age of 50 years. Many clinical studies have indicated that HIV infection, as well as components of HAART, can increase the risk in these individuals to a variety of noninfectious complications, including a risk to bone health. There is a significant need for detailed mechanistic analysis of the aging, HIV-infected population regarding the risk of HIV infection and therapy in order to maintain bone health. Insights from basic mechanistic studies will help to shed light on the role of HIV infection and the components of HAART that impact bone health, and will help in identifying preventative countermeasures, particularly for individuals 50 years of age and older.
\end{abstract}

Keywords: osteopenia, osteomalacia, osteoporosis, bisphosphonates, tenofovir, osteoimmunology

\section{Introduction}

There has been little research into how human immunodeficiency virus (HIV) infection and the aging process together influence the health and well being of infected individuals, which poses many challenges for health care providers, as well as for policy makers. ${ }^{1}$ Given the advent of highly active antiretroviral therapy (HAART) about two decades ago, HIV-infected individuals have a significantly improved long-term survival, with many of those affected now aged 50 years and older. HIV infection and its treatment have increasingly led to concerns over comorbidities, such as cardiovascular disease, cancer, depression, dementia, and bone mineral density loss. Such concerns parallel the general concerns regarding the health and well being in the aging population. In the US, data from the Centers for Disease Control have indicated that individuals aged 50 years and older represent $29 \%$ of those living with acquired immunodeficiency syndrome (AIDS), $24 \%$ of those living with HIV/AIDS, and $15 \%$ of new HIV/AIDS diagnoses. ${ }^{2}$ The rates among African-Americans and Hispanic-Americans are 12 times and five times greater, respectively. It has been estimated that by $2015,50 \%$ of individuals living with HIV/AIDS will be 50 years of age or older. ${ }^{3}$ These epidemiologic data indicate that the HIV epidemic in the US and other countries with access to HAART will cause a change in the nature of HIV clinics, changing the focus from health concerns in younger patients to a broader age range, with an increasing focus on geriatric issues, including issues relating to bone health.
Correspondence: Kim C Mansky University of Minnesota, 16-146 Moos Tower, 5 I 5 Delaware St SE, Minneapolis, MN 55455, USA

Tel +l 6I26265582

$\mathrm{Fax}+\mathrm{I} 6126265515$

Email kmansky@umn.edu 


\section{Basic bone biology and pathology}

Bone is a dynamic tissue in the body that is formed and maintained by two cell types, ie, osteoblasts (which form bone) and osteoclasts (which resorb bone). There is an extensive cell-signaling network between osteoblasts and osteoclasts required for maintaining the balance of activities of these two cell types that is crucial for bone remodeling and bone health. Direct signals between bone cells have recently been implicated as being important for regulating bone remodeling. ${ }^{4-6}$ For instance, osteoclasts can initiate bone formation via signaling to osteoblasts, independent of their ability to resorb bone. ${ }^{7,8}$ It has been demonstrated in patients with autosomal dominant osteopetrosis Type II that the number of osteoclasts, but not their activity, controls bone formation. ${ }^{9}$ In contrast, osteoblasts regulate osteoclast differentiation by expressing two factors that are necessary and sufficient for osteoclast formation, ie, $\mathrm{M}-\mathrm{CSF}^{10}$ and RANKL. ${ }^{11}$

\section{Measurement of bone health}

Several different methods are used to measure bone density. These include dual-energy X-ray absorptiometry, quantitative computed tomography, and quantitative ultrasound. While dual-energy X-ray absorptiometry is typically the most common method used and is considered the gold standard for measuring bone density, quantitative computed tomography and quantitative ultrasound can provide other useful information. Quantitative computed tomography provides measurements of cortical and trabecular volumetric bone mineral density, and studies have found using quantitative computed tomography that individual subregions of trabecular and cortical compartments are independent predictors of hip fracture and have differential responses to osteoporosis treatments. ${ }^{12,13}$ Quantitative ultrasound can provide further information on bone fragility and fracture risk, particularly in postmenopausal women. ${ }^{14-16}$ Both the spine and femur are common sites of analysis, and both regions contain cortical bone (dense outer shell) as well as trabecular bone (interconnecting sponge-like bony sheets), although the spine has relatively more cancellous bone, which can undergo the highest rate of bone turnover. Osteopenia and osteoporosis are diagnosed by comparing bone mineral density of an individual with expected normal values. The $\mathrm{T}$ score represents the number of standard deviation differences between an individual's bone mineral density versus that of the mean of the population at peak bone mass. The $T$ score creates a foundation for comparison of individuals as having osteopenia or osteoporosis, and can be of practical utility in predicting subsequent risk of fracture in men and women 50 years of age and older.

A recent report has described the use of the World Health Organization's FRAX equation as a first-line screening of bone metabolism alteration in the HIV-infected population. ${ }^{1718}$ FRAX is a computer-based algorithm that calculates the 10-year probability of fractures in men and women on the basis of classic risk factors alone or by integration with bone mineral density, which is measured by dual-energy X-ray absorptiometry. The FRAX algorithm has been proposed as a screening tool for HIV-positive individuals to identify those who have an increased clinical risk of fractures and for where bone mineral density measurements are strongly recommended. In a study of a mostly male population, reduced bone mineral density was significantly associated with particular HAART regimens. FRAX analysis of the entire population indicated a $1.2 \%$ increased risk of hip fracture and a 5.4\% increased risk for major osteoporotic fracture. ${ }^{17}$ Further FRAX analysis indicated that there were 22 of 139 patients in the study (15.8\%) who had a $17.5 \%$ increased risk of major osteoporotic fracture and three patients (2.2\%) who had a $120 \%$ increased risk of major fracture.

Perturbation in the function of either osteoblasts or osteoclasts can result in bone density loss, presenting clinically as osteopenia or osteoporosis. Osteoporosis occurs during aging and is commonly associated with women following menopause (on average at age 51 years), where it is called postmenopausal osteoporosis, but it can also occur in men or anyone with certain hormonal disorders, other chronic diseases, or as a result of medications such as glucocorticoids. ${ }^{19-25}$

\section{HIV infection as a risk factor for bone health}

There is clearly a large body of literature implicating a number of general factors associated with low bone mineral density in the general population, in particular those aged 50 years and older. ${ }^{26-29}$ One in two women and one in five men over the age of 50 years are expected to suffer a bone fracture due to osteoporosis during their remaining lifetime. ${ }^{30} \mathrm{~A}$ current question that requires much more intensive investigation is whether HIV infection is a risk factor for low mineral density and the mechanisms involved. For HIV-infected individuals, HIV infection has been implicated as a risk factor for alteration of bone mineral density. ${ }^{31-34}$ Clearly, there are general effects of HIV infection that can be risk factors for low bone mineral density. These include a low 
body mass index, physical inactivity, malabsorption, and hypogonadism (Table 1). The HIV-infected population has been reported as having high rates of vitamin D deficiency, smoking, and drug and alcohol abuse, which are general risk factors for osteoporosis (Table 1). ${ }^{35}$ Immune cells may also influence bone mineral density. ${ }^{36}$ The loss of both immunocompetence and bone mineral density are common during aging. Importantly, both are associated with HIV infection and AIDS pathogenesis, and in some respects can resemble accelerated aging. ${ }^{37}$ It is plausible that HIV infection could therefore accelerate the aging process. ${ }^{38}$

Mechanistic details regarding how HIV infection may reduce bone mineral density are quite limited, with minimal follow-up and demonstration of clearly identified mechanisms. However, the limited literature would support the general model that HIV infection could impact the immune system, which would then influence the skeletal system.

During aging, the reduction in T cell renewal along with the progressive enrichment of terminally differentiated $\mathrm{T}$ cells results in a general decline of the immune system, leading to immunosenescence. Inflammation is a clear hallmark of age-associated comorbidities, and immune activation is a well established hallmark of HIV infection. ${ }^{39}$ Constant stimulation of the immune system by HIV can activate the innate and adaptive immune system. This activation results in the release of the mediators of inflammation, eg, cytokines. HIV-mediated immune activation, along with lack of antiinflammatory responses, is a likely driver of accelerated aging as a result of HIV infection, even during HAART-suppressed HIV replication. Age-associated defects have been observed in the activation of cells in the innate immune system. ${ }^{40}$ Aging is characterized by a constitutive proinflammatory environment in which persistent low-grade innate immune activation could enhance cellular, tissue, and organ damage by HIV infection, including that of the skeletal system.

Osteoimmunology is an interdisciplinary research area that studies the interface and cross-talk between the skeletal and immune systems. ${ }^{41,42}$ In particular, osteoimmunology

Table I General risk factors associated with human immunodeficiency virus infection to bone mineral density loss

\begin{tabular}{l} 
General risk factors \\
\hline Low body mass index \\
Physical inactivity \\
Malabsorption \\
Hypogonadism \\
Vitamin D deficiency \\
Smoking \\
Drug and alcohol abuse
\end{tabular}

focuses on the shared components and mechanisms between the two systems, which include ligands, receptors, signaling molecules, and transcription factors. Bone marrow is important for the proper development of the immune system, and has important stem cells that maintain the immune system. Cytokines produced by immune cells (eg, RANKL, macrophage colony-stimulating factor, tumor necrosis factor alpha [TNF- $\alpha]$, interleukins, and interferons) can also have important effects on regulating bone homeostasis. The balance between bone modeling and remodeling can be perturbed during chronic inflammation, which can lead to bone metabolic disorders as well as bone pain.

Some of the available literature shows a preliminary connection between HIV infection and osteoimmunology. For example, it has been suggested that there is an association between chronic inflammatory conditions and osteoporosis, and that RANKL is produced by activated T cells, although no studies have provided mechanistic details to support this suggestion. ${ }^{43}$ During the asymptomatic phase of HIV infection, levels of inflammatory cytokines, such as interleukin-1, interleukin-6, and TNF- $\alpha$ are increased, and these cytokines can also stimulate bone resorption. ${ }^{43}$ RANKL levels have been found to be higher in HIV-infected men and correlated with lower bone mineral density, ${ }^{44}$ although another study found that bone mineral density was not associated with soluble TNF receptor 2 levels. ${ }^{45}$ Well-controlled studies have not been performed to date to demonstrate a connection between altered expression of cytokines due to HIV infection and changes in bone mineral density. Such studies, particularly using well-defined animal models, would be important studies to perform in order to provide clear evidence in support of a cytokine-HIV infection-bone mineral density connection. In Figure 1, a general model is proposed for how HIV infection is connected to bone mineral density loss via cell signaling. Future experiments are needed to test and refine this model.

A few other reports provide connections, the underlying mechanisms of which remain unclear and a model to associate viral infection with bone mineral density loss is not obvious. First, an older report suggested reduced bone formation and turnover in iliac crest biopsies ${ }^{46}$ but no follow-up on these studies has confirmed these observations. Further studies suggest other possible interactions between HIV infection, TNF- $\alpha$, and bone mineral density. In one report, TNF- $\alpha$ has been reported to mediate apoptosis of human osteoblasts in response to HIV gp $120 .{ }^{47}$ If confirmed, this observation could be an important connection between HIV infection and osteoblasts. Another observation found that vitamin D 


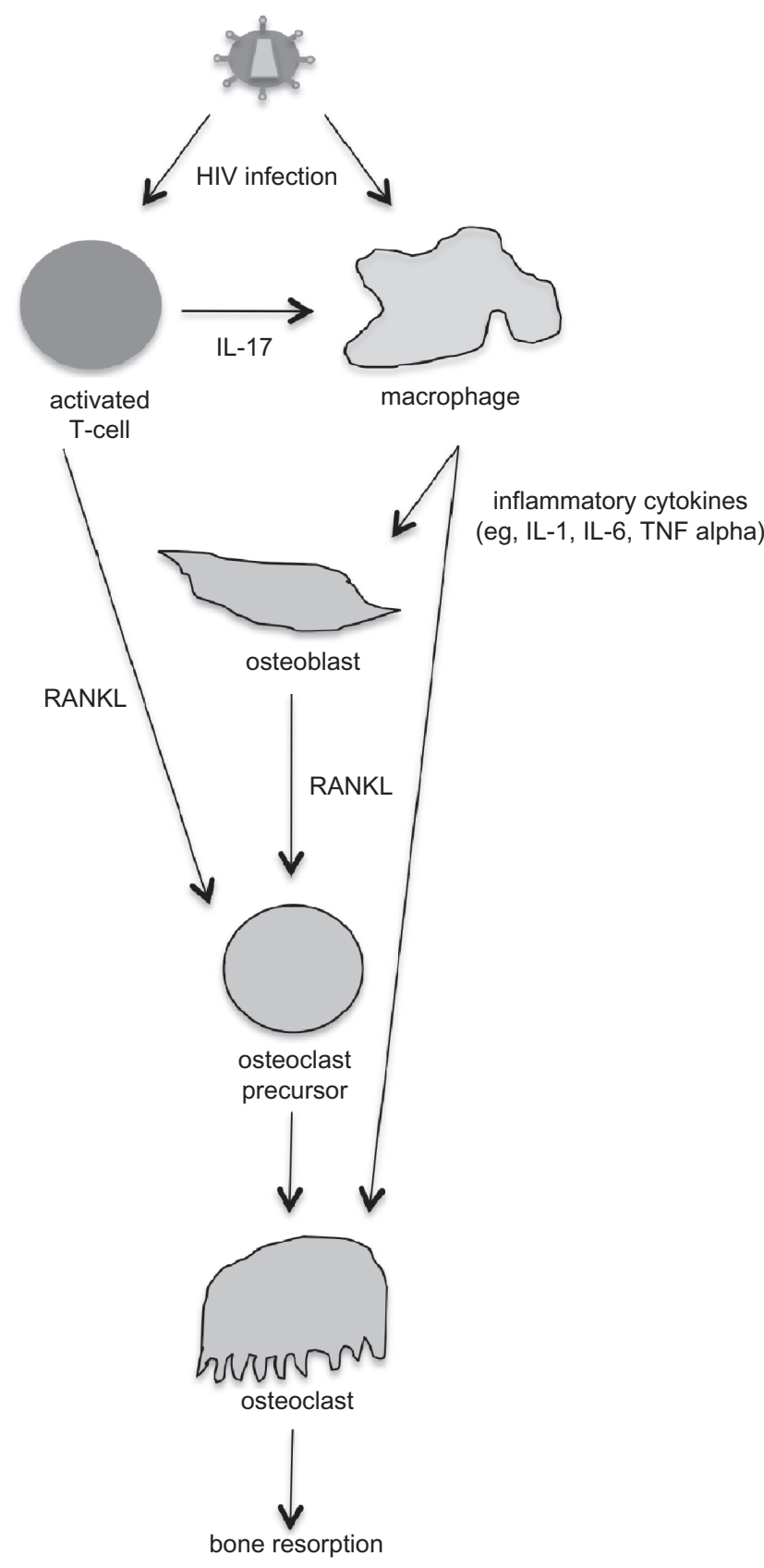

Figure I Proposed model for how human immunodeficiency virus (HIV) infection is associated with bone mineral density loss. HIV can infect both activated T cells and macrophages. HIV-infected T cells express interleukin (IL)- I7, which stimulates HIV-infected macrophages to produce inflammatory cytokines, including IL-I, IL-6, and tumor necrosis factor (TNF). The inflammatory cytokines can stimulate both osteoblasts and osteoclasts. HIV-infected activated T cells and osteoblasts produce RANKL, which further stimulates osteoclastogenesis. Overproduction of osteoclast activity results in an imbalance in bone remodeling and increases bone resorption.

deficiency is common among HIV-infected individuals, and a suggestion is that inhibition of 1-alpha-hydroxylase by TNF- $\alpha$ may have contributed to this. ${ }^{48}$

In summary, imbalances in growth factors and cytokines could contribute to bone mineral density loss by increasing bone resorption, as indicated in the model proposed in the Figure. However, it is clear that most of these data are suggestive and correlative, and there remains a strong need for very careful examination of potential mechanisms that can directly link HIV infection to bone mineral density loss. ${ }^{49}$ The study of osteoimmunology in the context of HIV infection provides fertile ground for enhancing our understanding of the fundamental mechanisms that may connect HIV infection with bone metabolism.

\section{HAART as a risk to bone health}

Several of the drug classes that comprise HAART have been implicated as risk factors for low bone mineral density (Table 2). Several of the HIV protease inhibitors have been shown to alter bone mineral density. ${ }^{50}$ Recent gene expression profiling has indicated that exposure of osteoblastic cells to nelfinavir and ritonavir increases gene expression of the inflammatory cytokines, MCP-1, and interleukin- $8 .^{51}$ Protease inhibitors have also been suggested to inhibit 1 -alpha-hydroxylase, as well as to reduce $1,25(\mathrm{OH})_{2} \mathrm{D}$ levels, which could reduce bone mineral density. ${ }^{45}$ LRP5, a positive regulator of bone formation, is inhibited by protease inhibitors. ${ }^{51,52}$

Reverse transcriptase inhibitors are another class of anti-HIV drugs that have been implicated in bone metabolism. For example, azidothymidine, a nucleoside reverse transcriptase inhibitor, has been suggested to stimulate osteoclastogenesis in vitro and reduce bone mineral density in mice. ${ }^{53}$ Some nucleoside reverse transcriptase inhibitors have been implicated in causing mitochondrial damage and dysfunction due to their cross-inhibition of mitochondrial DNA polymerase. ${ }^{51,53}$ This could be responsible for the raised lactate levels observed in some HIV-infected individuals who are on HAART, which has been associated with increased bone resorption. ${ }^{54}$ Efavirenz, a non-nucleoside reverse transcriptase inhibitor, has been reported to reduce vitamin D levels by inducing hepatic enzymes. ${ }^{55}$

Some of the strongest data in support of the components of HAART being associated with bone mineral density reductions have been observed with tenofovir, a nucleotide reverse transcriptase inhibitor, and been reported in human adults. ${ }^{56}$ Increased bone resorption could cause a compensa-

Table 2 Drug classes in highly active antiretroviral therapy that have been implicated as risk factors for bone mineral density

\section{Drug type}

Protease inhibitors

Nucleoside/nucleotide reverse transcriptase inhibitors

Non-nucleoside reverse transcriptase inhibitors 
tory increase in osteoblast activity, which would be revealed by increased serum alkaline phosphatase levels. ${ }^{57}$ Tenofovir treatment decreased bone mineral density, as well as increased urinary calcium excretion. Previous studies in macaques have demonstrated adverse effects on bone mineral density from the administration of tenofovir. ${ }^{58-60}$ Simian immunodeficiency virus infection of macaques was also implicated in decreasing bone mineral density. Histomorphometric analysis in one of these studies revealed an increase in tibial osteoid seam width, which can result in bone softening and can develop into osteomalacia. ${ }^{58}$ The increase in osteoid seam width is likely to be associated with reduced activity in osteoblasts.

The gene expression profile of primary osteoclasts and osteoblasts has been evaluated ex vivo following tenofovir exposure. ${ }^{61,62}$ Specific downregulation of Gnas, Got2, and Snord32a was observed in osteoclasts. The downregulation of Gnas gene expression may result in less mitogen-activated protein kinase/extracellular signal-regulated kinase signaling and ultimately a reduction in osteoclast proliferation and actin filament formation, resulting in decreased bone resorption. Got 2 is a mitochondrial enzyme involved in energy transduction, specifically amino acid metabolism as well as the urea and tricarboxylic acid cycles. Perturbation of amino acid metabolism following exposure to tenofovir in both osteoblasts and osteoclasts suggests alteration in bone homeostasis. Over 70 genes had their gene expression altered in primary osteoblasts following tenofovir exposure. The changes in gene expression profiles involved in cell signaling, cell cycle, and amino acid metabolism, would likely impact osteoblast function in bone formation.

The association of tenofovir with mitochondrial dysfunction has been investigated. In general, no mitochondrial dysfunction was observed with tenofovir. ${ }^{63-66}$ Other studies have reported a lowering of mitochondrial dysfunction when drug regimens were changed and nucleoside reverse transcriptase inhibitors were replaced with tenofovir. ${ }^{67-69}$ Potential mechanisms for tenofovir-associated bone loss include preferential uptake by osteoclasts (altering gene expression resulting in increased bone resorption), uptake by osteoblasts (altering gene expression decreasing bone formation), and uptake by both osteoclasts and osteoblasts (altering gene expression of both cells types and ultimately the balance between bone resorption and bone formation, resulting in bone loss). ${ }^{70}$ The loss of bone density due to tenofovir exposure could also be associated with tenofovir-induced renal dysfunction, particularly renal proximal tubule dysfunction. ${ }^{17,57,71-79}$ The failure of renal proximal tubular cells to reabsorb filtered bicarbonate from urine would result in urinary bicarbonate wasting and subsequent acidemia and a more general dysfunction of the proximal tubular cell, a clinical condition called Fanconi syndrome. Commonly observed clinical features in Fanconi syndrome include aminoaciduria, glycosuria, tubular proteinuria, and uricosuria. Importantly, the main pathology observed in Fanconi syndrome is bone demineralization (osteomalacia or rickets) due to phosphate wasting. Therefore, tenofovir-associated bone density loss may be an outcome of renal dysfunction.

\section{Treatment of bone mineral density loss from HIV infection and HAART}

The treatment of low bone mineral density requires a complete investigation into its etiology. Secondary causes and complications, particularly relevant for individuals 50 years of age and older, including chronic liver disease, chronic malnutrition, hyperthyroidism, hypogonadism, and Type 1 diabetes, require identification and treatment where possible. ${ }^{80-82}$ Low vitamin D levels should be followed up by analysis of parathyroid hormone, with the goal of attempting to normalize vitamin $\mathrm{D}$ and parathyroid hormone levels. Diagnosis of osteoporosis, which would typically be established by a $\mathrm{T}$ score $<2.5$ for those 50 years of age and older, would warrant treatment with bisphosphonates in conjunction with vitamin D, calcium supplementation, and strategies geared towards trying to minimize the risk of falls.

Bisphosphonates are synthetic analogs of inorganic pyrophosphate. ${ }^{83-85}$ They inhibit bone resorption by increasing the apoptosis of osteoclasts. To date, preliminary data suggest that the use of bisphosphonates is effective in increasing bone mineral density in the presence of HAART ${ }^{86-88}$ The bisphosphonates, including alendronate $\left(\right.$ Fosamax $\left.^{\circledR}\right)$, ibandronate $\left(\right.$ Boniva $\left.^{\circledR}\right)$, risedronate $\left(\right.$ Actonel $\left.^{\circledR}\right)$, and zoledronate $\left(\right.$ Aclasta $^{\circledR}$, Zometa $\left.^{\circledR}\right)$ are all available as options for use in the treatment of bone mineral density loss. ${ }^{83-85}$ There are concerns regarding the use of bisphosphonates in the treatment of bone mineral density loss that occurs in HIV-infected individuals. One major concern is that the oral administration of bisphosphonates requires a very complex dosing regimen, ie, the bisphosphonate must be taken fasting, with the individual sitting or standing, with a large glass of water, and then the individual must remain upright for 30-60 minutes after taking the medication, without eating or drinking or taking other medications during that time. Another concern is the long-term administration of bisphosphonates in the context of HIV infection and HAART. To date, alendronate has been the most extensively used bisphosphonate in the treatment of bone mineral density loss in the context of HIV infection. ${ }^{89,90}$ 
However, there has not been enough statistical power in the relevant research to conclude that fracture rates are lowered. This should be a priority of future clinical studies.

\section{Conclusion}

The specific role(s) of HIV infection in bone mineral loss remains poorly characterized, and further studies are needed to identify the underlying mechanisms. The use of appropriate animal models would be highly desirable in this regard. The role of specific HAART regimens in increased risk of bone mineral density loss has been suggested but not fully analyzed, particularly in the context of many of the newly approved antiHIV drugs available. Further studies are needed to investigate whether declines in bone mineral density are greater in individuals over 50 years of age receiving HAART compared with the non-HIV-infected population to aid further in identifying potential risk factors. ${ }^{91}$ The rate of bone mineral density loss is an important parameter to determine in the identification of possible treatments using bisphosphonates. A relatively slow decline in bone mineral density loss could allow for bisphosphonates, such as zoledronate, to be used as an adjuvant therapy along with HAART. Given that the HIV-infected population is aging and many patients are now reaching the age of 50 years, there needs to be serious consideration of the impact of HIV infection and HAART on the health of those affected, particularly in the area of bone health.

\section{Acknowledgment}

The author's research is supported by National Institutes of Health grants AR53946 and AR056642.

\section{Disclosure}

The author reports no conflict of interest in this work.

\section{References}

1. Henry K. Internal medicine/primary care reminder: What are the standards of care for HIV-positive patients aged 50 years and older? Curr HIV/AIDS Rep. 2009;6(3):153-161.

2. Centers for Disease Control and Prevention. HIV+ persons aged 50 and over. Available at: http://www.cdc.gov/hiv/topics/over50/index.htm. Centers for Disease Control and Prevention. Accessed Aug 18, 2010.

3. Graying plague: By 2015 over half of HIV in US will be in those over 50. Late diagnoses contribute to problem. AIDS Alert. 2010;25(3):25-28.

4. Karsdal MA, Martin TJ, Bollerslev J, Christiansen C, Henriksen K. Are nonresorbing osteoclasts sources of bone anabolic activity? J Bone Miner Res. 2007;22(4):487-494.

5. Karsdal MA, Henriksen K, Sorensen MG, et al. Acidification of the osteoclastic resorption compartment provides insight into the coupling of bone formation to bone resorption. Am J Pathol. 2005;166(2): 467-476.

6. Martin TJ, Sims NA. Osteoclast-derived activity in the coupling of bone formation to resorption. Trends Mol Med. 2005;11(2):76-81.
7. Bollerslev J, Marks SC Jr, Pockwinse S, et al. Ultrastructural investigations of bone resorptive cells in two types of autosomal dominant osteopetrosis. Bone. 1993;14(6):865-869.

8. Bollerslev J, Steiniche T, Melsen F, Mosekilde L. Structural and histomorphometric studies of iliac crest trabecular and cortical bone in autosomal dominant osteopetrosis: A study of two radiological types. Bone. 1989;10(1):19-24.

9. Alatalo SL, Ivaska KK, Waguespack SG, Econs MJ, Vaananen HK, Halleen JM. Osteoclast-derived serum tartrate-resistant acid phosphatase $5 \mathrm{~b}$ in Albers-Schonberg disease (type II autosomal dominant osteopetrosis). Clin Chem. 2004;50(5):883-890.

10. Cecchini MG, Hofstetter W, Halasy J, Wetterwald A, Felix R. Role of CSF-1 in bone and bone marrow development. Mol Reprod Dev. 1997;46(1):75-83; discussion 83-74.

11. Wada T, Nakashima T, Hiroshi N, Penninger JM. RANKL-RANK signaling in osteoclastogenesis and bone disease. Trends Mol Med. 2006;12(1):17-25.

12. Black DM, Greenspan SL, Ensrud KE, et al. The effects of parathyroid hormone and alendronate alone or in combination in postmenopausal osteoporosis. N Engl J Med. 2003;349(13):1207-1215.

13. Black DM, Bouxsein ML, Marshall LM, et al. Proximal femoral structure and the prediction of hip fracture in men: A large prospective study using QCT. J Bone Miner Res. 2008;23(8):1326-1333.

14. Gluer CC. Quantitative ultrasound techniques for the assessment of osteoporosis: Expert agreement on current status. The International Quantitative Ultrasound Consensus Group. J Bone Miner Res. 1997; 12(8):1280-1288.

15. Guglielmi G, Scalzo G, de Terlizzi F, Peh WC. Quantitative ultrasound in osteoporosis and bone metabolism pathologies. Radiol Clin North Am. 2010;48(3):577-588.

16. Lee HD, Hwang HF, Lin MR. Use of quantitative ultrasound for identifying low bone density in older people. J Ultrasound Med. 2010; 29(7):1083-1092.

17. Calmy A, Fux CA, Norris R, et al. Low bone mineral density, renal dysfunction, and fracture risk in HIV infection: A cross-sectional study. J Infect Dis. 2009;200(11):1746-1754.

18. Gazzola L, Comi L, Savoldi A, et al. Use of the FRAX equation as first-line screening of bone metabolism alteration in the HIV-infected population. J Infect Dis. 2010;202(2):33-1; author reply 331-332.

19. Bonnelye E, Merdad L, Kung V, Aubin JE. The orphan nuclear estrogen receptor-related receptor alpha (ERRalpha) is expressed throughout osteoblast differentiation and regulates bone formation in vitro. $J$ Cell Biol. 2001;153(5):971-984.

20. Liu RH, Werth VP. What is new in the treatment of steroid-induced osteoporosis? Semin Cutan Med Surg. 2007;26(4):203-209.

21. Shaker JL, Lukert BP. Osteoporosis associated with excess glucocorticoids. Endocrinol Metab Clin North Am. 2005;34(2):341-356, viii-ix.

22. Caplan L, Saag KG. Glucocorticoids and the risk of osteoporosis. Expert Opin Drug Saf. 2009;8(1):33-47.

23. Ebeling PR. Osteoporosis in men. New insights into aetiology, pathogenesis, prevention and management. Drugs Aging. 1998;13(6): 421-434.

24. McIlwain HH. Glucocorticoid-induced osteoporosis: Pathogenesis, diagnosis, and management. Prev Med. 2003;36(2):243-249.

25. Pietschmann P, Rauner M, Sipos W, Kerschan-Schindl K. Osteoporosis: An age-related and gender-specific disease - a mini-review. Gerontology. 2008;55(1):3-12.

26. Compston J. Osteoporosis: Social and economic impact. Radiol Clin North Am. 2010;48(3):477-482.

27. Looker AC, Melton LJ 3rd, Harris TB, Borrud LG, Shepherd JA. Prevalence and trends in low femur bone density among older US adults: NHANES 2005-2006 compared with NHANES III. J Bone Miner Res. 210;25(1):64-71.

28. Goodfellow LR, Earl S, Cooper C, Harvey NC. Maternal diet, behaviour and offspring skeletal health. Int J Environ Res Public Health. 2010;7(4):1760-1772. 
29. Winsloe C, Earl S, Dennison EM, Cooper C, Harvey NC. Early life factors in the pathogenesis of osteoporosis. Curr Osteoporos Rep. 2009; 7(4):140-144.

30. WHO. Assessment of fracture risk and its application to screening for postmenopausal osteoporosis. Report of a WHO Study Group. World Health Organ Tech Rep Ser. 1994;843:1-129.

31. Arpadi SM, Horlick M, Thornton J, Cuff PA, Wang J, Kotler DP. Bone mineral content is lower in prepubertal HIV-infected children. J Acquir Immune Defic Syndr. 2002;29(5):450-454.

32. Tebas P, Powderly WG, Claxton S, et al. Accelerated bone mineral loss in HIV-infected patients receiving potent antiretroviral therapy. AIDS 2000;14(4):F63-F67.

33. Vigano A, Mora S. Adverse effects of antiretroviral therapy: Focus on bone density. Expert Opin Drug Saf. 2004;3(3):199-208.

34. Madeddu G, Spanu A, Solinas P, et al. Bone mass loss and vitamin D metabolism impairment in HIV patients receiving highly active antiretroviral therapy. QJ Nucl Med Mol Imaging. 2004;48(1):39-48.

35. Amorosa V, Tebas P. Bone disease and HIV infection. Clin Infect Dis. 2006;42(1):108-114

36. Li Y, Toraldo G, Li A, et al. B cells and T cells are critical for the preservation of bone homeostasis and attainment of peak bone mass in vivo. Blood. 2007;109(9):3839-3848.

37. Deeks SG. Immune dysfunction, inflammation, and accelerated aging in patients on antiretroviral therapy. Top HIV Med. 2009;17(4):118-123.

38. Nguyen N, Holodniy M. HIV infection in the elderly. Clin Interv Aging 2008;3(3):453-472.

39. Desai S, Landay A. Early immune senescence in HIV disease. Curr HIV/AIDS Rep. 2010;7(1):4-10.

40. Shaw AC, Joshi S, Greenwood H, Panda A, Lord JM. Aging of the innate immune system. Curr Opin Immunol. Jul 26, 2010. [Epub ahead of print].

41. Raggatt LJ, Partridge NC. Cellular and molecular mechanisms of bone remodelling. J Biol Chem. 2010;13;285(33):25103-25108.

42. Takayanagi H. Osteoimmunology and the effects of the immune system on bone. Nat Rev Rheumatol. 2009;5(12):667-676.

43. Raisz LG. Pathogenesis of osteoporosis: Concepts, conflicts, and prospects. J Clin Invest. 2005;115(12):3318-3325.

44. Gibellini D, Borderi M, de Crignis E, et al. RANKL/OPG/TRAIL plasma levels and bone mass loss evaluation in antiretroviral naive HIV-1-positive men. J Med Virol. 2007;79(10):1446-1454.

45. Chirch LM, Feiner J, Go R, et al. Osteopenia in patients with HIV infection is not associated with elevated sTNFR2 levels. Clin Infect Dis. 2006;43(8):1084-1085.

46. Serrano S, Marinoso ML, Soriano JC, et al. Bone remodelling in human immunodeficiency virus-1-infected patients. A histomorphometric study. Bone. 1995;16(2):185-191.

47. Gibellini D, de Crignis E, Ponti C, et al. HIV-1 triggers apoptosis in primary osteoblasts and HOBIT cells through TNFalpha activation. J Med Virol. 2008;80(9):1507-1514.

48. Villamor E. A potential role for vitamin D on HIV infection? Nutr Rev. 2006;64(5 Pt 1):226-233.

49. Vikulina T, Fan X, Yamaguchi M, et al. Alterations in the immunoskeletal interface drive bone destruction in HIV-1 transgenic rats. Proc Natl Acad Sci U S A. 2010;107(31):13848-13853.

50. Brown TT, Qaqish RB. Antiretroviral therapy and the prevalence of osteopenia and osteoporosis: A meta-analytic review. AIDS. 2006; 20(17):2165-2174.

51. Malizia AP, Vioreanu MH, Doran PP, Powderly WG. HIV1 protease inhibitors selectively induce inflammatory chemokine expression in primary human osteoblasts. Antiviral Res. 2007;74(1):72-76.

52. Tran H, Robinson S, Mikhailenko I, Strickland DK. Modulation of the LDL receptor and LRP levels by HIV protease inhibitors. J Lipid Res. 2003;44(10):1859-1869.

53. Pan G, Yang Z, Ballinger SW, McDonald JM. Pathogenesis of osteopenia/osteoporosis induced by highly active anti-retroviral therapy for AIDS. Ann NY Acad Sci. 2006;1068:297-308.
54. Carr A, Miller J, Eisman JA, Cooper DA. Osteopenia in HIV-infected men: Association with asymptomatic lactic acidemia and lower weight pre-antiretroviral therapy. AIDS. 2001;15(6):703-709.

55. Gyllensten K, Josephson F, Lidman K, Saaf M. Severe vitamin D deficiency diagnosed after introduction of antiretroviral therapy including efavirenz in a patient living at latitude 59 degrees N. AIDS. 2006; 20(14):1906-1907.

56. Gallant JE, Staszewski S, Pozniak AL, et al. Efficacy and safety of tenofovir DF vs stavudine in combination therapy in antiretroviralnaive patients: A 3-year randomized trial. JAMA. 2004;292(2): 191-201.

57. Fux CA, Rauch A, Simcock M, et al. Tenofovir use is associated with an increase in serum alkaline phosphatase in the Swiss HIV Cohort Study. Antivir Ther. 2008;13(8):1077-1082.

58. Castillo AB, Tarantal AF, Watnik MR, Martin RB. Tenofovir treatment at $30 \mathrm{mg} / \mathrm{kg} /$ day can inhibit cortical bone mineralization in growing rhesus monkeys (Macaca mulatta). J Orthop Res. 2002;20(6):1185-1189.

59. Tarantal AF, Marthas ML, Shaw JP, Cundy K, Bischofberger N. Administration of 9-[2-(R)-(phosphonomethoxy)propyl]adenine (PMPA) to gravid and infant rhesus macaques (Macaca mulatta): Safety and efficacy studies. J Acquir Immune Defic Syndr Hum Retrovirol. 1999;20(4): 323-333.

60. van Rompay KK, Brignolo LL, Meyer DJ, et al. Biological effects of short-term or prolonged administration of 9-[2-(phosphonomethox) propyl]adenine (tenofovir) to newborn and infant rhesus macaques. Antimicrob Agents Chemother. 2004;48(5):1469-1487.

61. Grigsby IF, Pham L, Gopalakrishnan R, Mansky LM, Mansky KC. Downregulation of Gnas, Got2 and Snord32a following tenofovir exposure of primary osteoclasts. Biochem Biophys Res Commun. 2010; 391(3):1324-1329.

62. Grigsby IF, Pham L, Mansky LM, Gopalakrishnan R, Carlson AE, Mansky KC. Tenofovir treatment of primary osteoblasts alters gene expression profiles: Implications for bone mineral density loss. Biochem Biophys Res Commun. 2010;394(1):48-53.

63. Vidal F, Domingo JC, Guallar J, et al. In vitro cytotoxicity and mitochondrial toxicity of tenofovir alone and in combination with other antiretrovirals in human renal proximal tubule cells. Antimicrob Agents Chemother. 2006;50(11):3824-3832.

64. Cihlar T, Birkus G, Greenwalt DE, Hitchcock MJ. Tenofovir exhibits low cytotoxicity in various human cell types: Comparison with other nucleoside reverse transcriptase inhibitors. Antiviral Res. 2002;54(1):37-45.

65. Birkus G, Hitchcock MJ, Cihlar T. Assessment of mitochondrial toxicity in human cells treated with tenofovir: Comparison with other nucleoside reverse transcriptase inhibitors. Antimicrob Agents Chemother. 2002; 46(3):716-723.

66. Biesecker G, Karimi S, Desjardins J, et al. Evaluation of mitochondrial DNA content and enzyme levels in tenofovir DF-treated rats, rhesus monkeys and woodchucks. Antiviral Res. 2003;58(3):217-225.

67. Gerschenson M, Kim C, Berzins B, et al. Mitochondrial function, morphology and metabolic parameters improve after switching from stavudine to a tenofovir-containing regimen. J Antimicrob Chemother. 2009;63(6):1244-1250.

68. Ribera E, Paradineiro JC, Curran A, et al. Improvements in subcutaneous fat, lipid profile, and parameters of mitochondrial toxicity in patients with peripheral lipoatrophy when stavudine is switched to tenofovir (LIPOTEST study). HIV Clin Trials. 2008;9(6):407-417.

69. Miro O, Garrabou G, Lopez S, et al. Short communication metabolic and mitochondrial effects of switching antiretroviral-experienced patients to enfuvirtide, tenofovir and saquinavir/ritonavir. Antivir Ther. 2006;11(5):625-630.

70. Grigsby IF, Pham L, Mansky LM, Gopalakrishnan R, Mansky KC. Tenofovir-associated bone density loss. Ther Clin Risk Manag. 2010;6:41-47.

71. Earle KE, Seneviratne T, Shaker J, Shoback D. Fanconi's syndrome in HIV+ adults: Report of three cases and literature review. J Bone Miner Res. 2004;19(5):714-721. 
72. Parsonage MJ, Wilkins EG, Snowden N, Issa BG, Savage MW. The development of hypophosphataemic osteomalacia with myopathy in two patients with HIV infection receiving tenofovir therapy. HIV Med. 2005;6(5):341-346.

73. Williams J, Chadwick DR. Tenofovir-induced renal tubular dysfunction presenting with hypocalcaemia. J Infect. 2006;52(4):e107-e108.

74. Nelson MR, Katlama C, Montaner JS, et al. The safety of tenofovir disoproxil fumarate for the treatment of HIV infection in adults: The first 4 years. AIDS. 2007;21(10):1273-1281.

75. Labarga P, Barreiro P, Martin-Carbonero L, et al. Kidney tubular abnormalities in the absence of impaired glomerular function in HIV patients treated with tenofovir. AIDS. 2009;23(6):689-696.

76. Kohler JJ, Hosseini SH, Hoying-Brandt A, et al. Tenofovir renal toxicity targets mitochondria of renal proximal tubules. Lab Invest. 2009; 89(5):513-519.

77. Woodward CL, Hall AM, Williams IG, et al. Tenofovir-associated renal and bone toxicity. HIV Med. 2009;10(8):482-487.

78. Perrot S, Aslangul E, Szwebel T, Caillat-Vigneron N, Le Jeunne C. Bone pain due to fractures revealing osteomalacia related to tenofovir-induced proximal renal tubular dysfunction in a human immunodeficiency virusinfected patient. J Clin Rheumatol. 2009;15(2):72-74.

79. Di Biagio A, Rosso R, Monteforte P, Russo R, Rovetta G, Viscoli C. Whole body bone scintigraphy in tenofovir-related osteomalacia: A case report. J Med Case Reports. 2009;3:8136.

80. McComsey GA, Huang JS, Woolley IJ, et al. Fragility fractures in HIVinfected patients: Need for better understanding of diagnosis and management. J Int Assoc Physicians AIDS Care (Chic Ill). 2004;3(3):86-91.

81. McComsey GA, Kendall MA, Tebas P, et al. Alendronate with calcium and vitamin D supplementation is safe and effective for the treatment of decreased bone mineral density in HIV. AIDS. 2007;21(18):2473-2482.
82. Wohl DA, McComsey G, Tebas P, et al. Current concepts in the diagnosis and management of metabolic complications of HIV infection and its therapy. Clin Infect Dis. 2006;43(5):645-653.

83. Drake MT, Clarke BL, Khosla S. Bisphosphonates: Mechanism of action and role in clinical practice. Mayo Clin Proc. 2008;83(9):1032-1045.

84. Drake MT, Cremers SC. Bisphosphonate therapeutics in bone disease: The hard and soft data on osteoclast inhibition. Mol Interv. 2010;10(3):141-152.

85. Russell RG. Bisphosphonates: From bench to bedside. Ann NY Acad Sci. 2006;1068:367-401.

86. Lin D, Rieder MJ. Interventions for the treatment of decreased bone mineral density associated with HIV infection. Cochrane Database Syst Rev. 2007(2):CD005645.

87. Bolland MJ, Grey AB, Horne AM, et al. Annual zoledronate increases bone density in highly active antiretroviral therapy-treated human immunodeficiency virus-infected men: A randomized controlled trial. J Clin Endocrinol Metab. 2007;92(4):1283-1288.

88. Huang J, Meixner L, Fernandez S, McCutchan JA. A double-blinded, randomized controlled trial of zoledronate therapy for HIV-associated osteopenia and osteoporosis. AIDS. 2009;23(1):51-57.

89. Clay PG, Voss LE, Williams C, Daume EC. Valid treatment options for osteoporosis and osteopenia in HIV-infected persons. Ann Pharmacother. 2008;42(5):670-679.

90. Paccou J, Viget N, Legrout-Gerot I, Yazdanpanah Y, Cortet B. Bone loss in patients with HIV infection. Joint Bone Spine. 2009;76(6): 637-641.

91. Onen NF, Overton ET, Seyfried W, et al. Aging and HIV infection: A comparison between older HIV-infected persons and the general population. HIV Clin Trials. 2010;11(2):100-109.
Clinical Interventions in Aging

\section{Publish your work in this journal}

Clinical Interventions in Aging is an international, peer-reviewed journal focusing on evidence-based reports on the value or lack thereof of treatments intended to prevent or delay the onset of maladaptive correlates of aging in human beings. This journal is indexed on PubMed Central, MedLine, the American Chemical Society's 'Chemical Abstracts

\section{Dovepress}

Service' (CAS), Scopus and the Elsevier Bibliographic databases. The manuscript management system is completely online and includes a very quick and fair peer-review system, which is all easy to use. Visit http://www.dovepress.com/testimonials.php to read real quotes from published authors. 